\title{
Editorial
}

\author{
Marc de Vries ${ }^{1}$
}

Published online: 7 January 2016

(C) Springer Science+Business Media Dordrecht 2016

I want to dedicate this Editorial to the memory of one of our editorial board members, who passed away on April 13, 2015, on her 61st birthday, after a period of illness: Chitra Natarajan. Probably most readers of our journal who knew her, will associate her name with the episteme conferences, of which she was one of the driving forces. Her background was in science education, but she has been of great value for the development and introduction of technology education in her country, India, and the impact of the research she did and supervised goes way beyond the boundaries of that country. Not only was she an excellent scholar, but also a warm and friendly person. As an international community in technology education research, we greatly regret the loss of this dear colleague. Our sincere condolences go to her partner, Raj Rajagopal. He has put together a wonderful collection of remembrances under the title of 'Embracing lives, chasing passions', which can be downloaded from the following site: http://www.chemicalweekly.com/knowgenix/ index.html. For those who knew her, this is really a great publication to read. It contains a description of her academic career and her accomplishments in science and technology education development and research, No less than 66 people wrote a short text with personal memories, to acknowledge what she has done for her direct environment, in particular the Homi Bhabha Centre for Science Education, but also worldwide. For more than twenty years, she worked with passion on creating education that would really be for the benefit of young people. A lot of pictures were included to remind us of the wonderful person she was. Her own voice is present in a series of selections from publications. It is hard to believe that she is no longer with us. As the editor-in-chief of this journal, I could always rely on her and her reviews were always of a high quality and aimed at helping the authors to get the best out of themselves. Thus they were treated exactly as Chitra's Ph.D. students, several of whom, like herself, also presented at international technology education conferences. The best way we can contribute to her remembrance is my following her

\section{Marc de Vries}

M.J.d.Vries@tue.nl

1 Eindhoven, The Netherlands 
example in continuously dedicating our efforts to the education of young people so that they can become the next generation of responsible citizens that live and work for a better world. Chitra left us with an outstanding example of how that can be done. In gratitude for what she did and who she was, we will continue our journey, also with this journal.

We also wave goodbye to some other board members with longstanding service who retreated because of retirement. They are John Gilbert, Dan Householder, Howard Middleton, Eric Parkinson and Mark Sanders. Vicky Compton also left the board, but for the sad reason that she was no longer employed in technology education, in spite of all the excellent work she did for the New Zealand technology education curriculum. We sincerely thank all these colleagues for their great contributions to the field, as well as their excellent reviews for this journal. We welcome new board members with whom I already have very promising first experiences. All other board members are also greatly thanked for their efforts on assuring the quality of this journal. The publication of the journal is only possible thanks to their much appreciated efforts. 